NASA Technical Memorandum 87285

\title{
Impact of the 1985 Space World Administrative Radio Conference on Frequency/Orbit Planning and Use
}

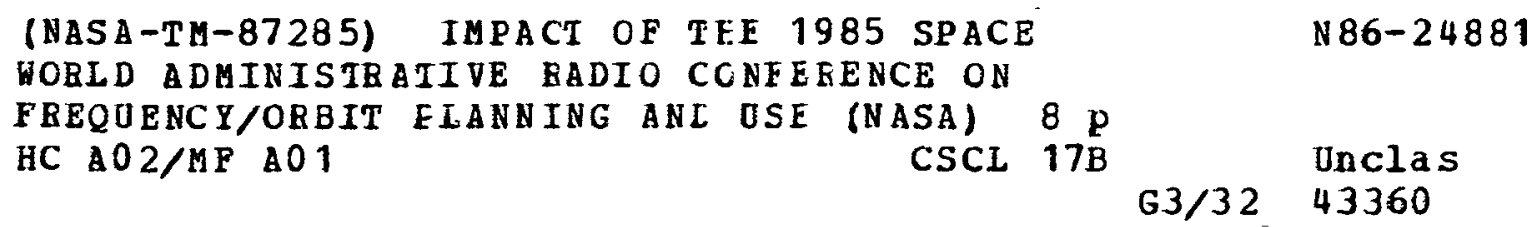

Edward F. Miller

Lewis Research Center

Cleveland, Ohio

Prepared for the

11th Annual Communications Satellite Systems Conference

sponsored by the American Institute of Aeronautics and Astronautics

San Diego, California, March 16-20, 1986 
IMPACT OF THE 1985 SPACE WORLD ADMINISTRATIVE RADIO CONFERENCE ON FREQUENCY/ORBIT PLANNING AND USE

\author{
Edward F. Miller \\ National Aeronautics and Space Administration \\ Lewis Research Center \\ Cleveland, Ohı 44135
}

\section{Abstract}

The 1985 World Administrative Radio Conference (WARC-ORB-85) was held to determine which space radio services should be planned and which planning methods should be used. The second session of this Conference (WARC-ORB-88) wlll meet to develop the required plans. This paper presents the results of WARC-ORB-85, assesses the impact of those decisions, and identifies the intersessional work to be conducted by administrations and the CCIR (Consultative Committee on International Rad 10).

The major decisions of WARC-ORB-85 were. (1) the restriction of additional planning to the fixed satellite service at identified frequencies, (2) the selection of a planning method consisting of two parts (a) an allotment plan, and (b) improved procedures. The paper also discusses WARC-ORB-85 decisions relative to the Region 2 broadcast satellite service plans at $12 \mathrm{GHz}$, feederlink planning for Regions 1 and 3 broadcast satellites at $12 \mathrm{GHz}$, and sound broadcast satellite service.

\section{Introduction}

The International Telecommunications Union (ITU), consisting of more than 160 member administrations, is engaged in an effort expected to result in the planning of portions of the geostationary orbit and the frequency spectrum used for space services. The ITU established a two-phase World Administrative Radio Conference (WARC) to accomplish this planning. The first session, WARC-ORB-85, was to identify the frequency bands and the space services to be planned, and the second session, WARC-ORB-88, was to perform that planning. This paper presents the results and impacts of the 1985 Space World Administrative Radio Conference, and discusses the work being performed in the intersessional period.

\section{Agenda for WARC-ORB-85}

The agenda for the first session of the Space WARC was established by the Administrative Council of the ITU.

Major elements were:

- Review of the situation prevailing.

- Decision on which space services and frequencies should be planned.

- Establishment of the principles, technical parameters, and criteria for planning.

- Identification of frequency bands where sharing criteria are needed.
- Establishment of guidelines for regulatory procedures for bands and services not subject to planning.

- Consideration of other approaches that would provide flexibility with changing services and technology.

- Feederlink planning in ITU regions 1 and 3 , for the broadcasting satellite service (BSS) at $12 \mathrm{GHz}$, as planned (downlink only) at WARC-77.

- Selection of frequency bands.

- Feederlink technical characteristics.

- Consideration of sound BSS and recommendations.

- Specification of intersessional work.

- Incorporation of the ITU Kegion 2 BSS plan into the Radio Regulations.

\section{Preparatory Work for WARC-ORB-85}

Preparations for the Space WARC in 1985 began more than two years prior to the Conference. International preparations culminated in the 1984 Conference Preparatory Meeting of the CCIR (Consultative Committee on International Radio). At this meeting, the relevant CCIR study groups developed the necessary technical information? to serve as the basis for WARC-85 decisions.

Individual administrations had also been engaged in preparations for the Space WARC. In the United States, government and industry advisory groups were formed to develop and assess technical information, evaluate alternatives, and establish formal positions prior to the Conference. In other countries the PTT's (Post, Telephone, and Telegraph organizations) played similar roles. Between and among administrations, bilateral and multilateral discussions were held to exchange views before the Conference.

In the final months before the Space WARC, .he United States delegation was formed consisting of 56 representatives of government and industry. The delegation finalized technical and political positions, prepared formal United States proposals to the Conference, and reviewed the proposals of other administrations. In other countries, simllar preparations were undertaken.

\section{Conference Setting}

The WARC-ORB-85 was held in Geneva, Switzerland with approximately 112 administrations in attendance. Twenty-three other organizations, such as INTELSAT, INTERSPUTNIK, EBU, and WMO, were present. More than 600 delegates were registered at the WARC-85. 
The remainder of this paper presents the results and impacts of the 1985 Space WARC and discusses the intersessional work and preparations to be conducted by administrations and the CCIR for the 1988 Space WARC.

\section{Resuits and Impacts of WARC-ORB-85}

The agenda topics discussed earlier fall quite naturally into categories that might be termed "Routine Matters" and "New Directions."

\section{Routine" Results}

An important task of WARC-ORB-85 was to incorporate into the Radio Regulations the Final Acts of the 1983 Regional Administrative Radio Conference, which had established a plan for broadcasting satellites at $12 \mathrm{GHz}$ in ITU Region 2 (the western hemisphere). After detalled technical discussions among administrations and the performance of additional computer analyses, the concerns of several European administrations were alleviated, and the Region 2 broadcasting satellite plan (both downlink and feederlink) was approved. The agreed upon plan is contained in the "Final Acts, WARC ORB-85".2 These revisions to the Radio Regulations are scheduled to become effective on October $30,1986$.

Another task of the Conference was to deal with feederlink planning for the broadcasting satellite service (BSS) at $12 \mathrm{GHz}$ in ITU Regions 1 and 3. The 1977 WARC had developed plans for BSS downlinks in these regions, but the corresponding feederlink plan had not yet been addressed in a WARC. The 1985 Space WARC decided that the frequency bands for Regiciss 1 and 3 feederlinks would be:

\section{3 - $18.1 \mathrm{GHz}$ (Preferred) \\ $14.5-14.8 \mathrm{GHz}$ (Outside Europe and for Malta)}

The WARC-ORB-85 also defined the technical characteristics for the feederlinks to Region 1 and 3 broadcasting satellites. (See Reference 3, for specific values of the technical parameters. It was decided that the International Frequency Registration Board (IFRB) would prepare the appropriate computer software to perform preliminary feederlink planning exercises prior to WARC-ORB-88. The ' 88 Conference would then develop and agree upon a feederlink assignment plan for Region 1 and 3 broadcasting satellites with $12 \mathrm{GHz}$ downlinks.

The 185 WARC was also to consider the area of the sound BSS, and to make appropriate recommendations to the ' 88 WARC. Most administrations saw difficulty in accommodating a potential allocation for the sound BSS in the frequency range 0.5 to $2.0 \mathrm{GHz}$. Agreement was reached to study a number of technical parameters that would more readily permit the implementation of the sound BSS. (See Reference 3, Section 7.2.4 for a listing of the study areas.) One of the more contentious areas selected for study was the frequency of operation. Agreement was finally reached to study "frequencies outside but near the $0.5-2.0 \mathrm{GHz}$ range where the possibilities for sharing or other accommodations may be greater." The frequency - allocation question for the sound BSS was referred to the ' 88 WARC.

\section{"New Directions"}

The more significant results of the WARC-ORB85 are in those areas where entirely new decisions were made, specifically, the decisions to plan particular space services in identified frequency bands.

Results. From an examination of the situation prevalling, the Conference made a decision to limit its planning activities to the fixed satellite service (FSS). This decision was based upon the degree of use, the state of technical development, the demand for orbit and frequency assignments, and other factors. It was concluded that, at the present time, only the FSS has sufficientiy high demand upon its resources and a sufficientiy high level of technical development to warrant planning.

The question of which frequency bands were to be planned was more contentious, and was not settled until the end of the Conference. Early in the Conference, the administrations split into two groups: those who argued for planning all frequencies assigned to the FSS, up to $20 \mathrm{GHz}$, and those who supported minimal planning. Arguments were presented supporting both points of view, but by the fourth week of the Conference no decision had been made on which frequency bands were to be planned. This fallure on the part of the planning committee of the Conference to reach a timely conclusion had a limiting effect on the work of the other committees. For example, the technical committee output was developed before the decision on frequencres and hence was quite general and not tallored to the specific frequency bands chosen for planning.

Eventually, on the last day of the Conference, the decision was reached on a planning method consisting of two parts: (a) an allotment plan and (b) improved procedures.

The allotment planning method described in Table 1 is associated with $C$ and Ku band frequencles. However, the specific frequencies identified are in what are commonly termed as "the expansion bands" or "the WARC 79 bands." Thus, the $\mathrm{C}$ and $\mathrm{Ku}$ band frequencles, which are presently being used quite intensively for FSS communications, are not subject to allotment planning. The allotment planning method will determine the use of and access to frequencres that are presentiy little used in the fixed satellite service.

The method of planning by improved procedures, described in Table II and Fig. 1, includes most of the other frequencies that are allocated to the FSS. The heavily used $C$ band frequencles (3700$4200 \mathrm{MHz}$ downlink and 5925-6425 MHz feederlink) are included in the frequencies covered by improved procedures. The 7 and $8 \mathrm{GHz}$ frequencies used by the military are not included under either planning method.

The WARC-ORB-85 also established planning principles to guide the development of both parts 
of the planning method. These eleven planning principles are summarized below:

1. Guarantee of access and equitability guarantee in practice for all countries equitable access to the geostationary satellite orbit and the frequency bands allocated to the space services utilizing it, taking into account the special needs of developing countries and the geographical situation of particular countries.

2. Sharing with other services - must not impose additional constraints on terrestrial and/ or space services sharing the band on an equal basis.

\section{Reservation of resources -}

(a) The planning method should consider the full orbit/spectrum resource. Setting aside portions of the resources to accommodate unforeseen requirements and requirements of future members of the Union shall be considered after all requirements are satisfied.

(b) Administrations or groups of administrations are not entitled to permanent priority in the use of particular frequencies and GSO positions in such a way as to foreclose access by other administrations to the GSO and frequency bands allocated to space services.

4. The technical aspects of special geographical situations - should be taken into account.

5. Consideration of existing systems - take into account the existing systems. If necessary, these systems may be subjected to some adjustments to allow for the accommodation of new systems.

\section{Provisions for multi-administration} systems

(a) shall take into account the requirements of administrations using multi-administration systems created by intergovernmental agreement and used collectively without affecting the rights of administrations with respect to national systems.

(b) shall take account of the specific characteristics of multi-administration systems in order to enable them to continue to meet the requirements of administrations for international services as well as, in many cases, for national services.

7. Flexibility - to accommodate unforeseen requirements and modification of requirements of administrations, and to accommodate advances in technology as well as to not prevent the use of technologies which are well proven and widely avallable.

8. Different planning solutions in different circumstances - as for different regions, frequency bands or orbital arcs shall not be excluded.

9. Efficiency - efficient and economical use of the geostationary orbit and frequency bands allocated to space services.
10. Provisions for multiservice and multiband networks - without imposing undue constraints to planning.

11. Administrative cost - for the development and application of the planning method to be as low as possible.

The difficult task of WARC-0RB- 88 will be to develop the appropriate planning methods that will be judged to be consistent with these planning principles, which are likely to be differently understood by the different administrations present. The task will then be to forge agreement from what may initially be substantial disagreement.

Impacts. The near term impacts of the dec 1sions of WARC-ORB-85 are (1) that a portion of the frequency bands allocated to the fixed satel11 te service will be subject to allotment planning, and (2) other FSS bands will benefit from improved procedures. These specific actions are scheduled to occur at WARC-ORB-88. Given a successful outcome of the 88 Space WARC, what will be the scenario for the affected bands in the fixed satellite service?

In the bands subject to allotment planning, each ITU member is targeted for a minimum of one allotment, with the full $800 \mathrm{MHz}$ bandwidth. The achievability of this goal is a function of the technical parameters selected as the basis for planning. If characteristics are chosen that are representative of yesterday's technology, then full bandwidth allotments may not be possible for areas where there is a high density of ITU members per degree of longitude, as for Europe/Africa and the Caribbean/Central America. On the other hand, the use of current technology or advanced technology with improved performance would al low closer spacings of satellites in the geostationary orbit and would be more likely to provide one full bandwidth allotment per ITU member. Detalled analyses of different planning scenarios, under different technical assumptions, are required to fully examine the possibilities.

For the FSS bands subject to improved procedures, the likely outcome of WARC-ORB-88 is a simplification and improvement of the processes required to obtain frequency assignments. Two very strong factors are pushing toward this outcome.

(1) A sincere desire on the part of member administrations of the ITU to change and simplify the present processes.

(2) A wealth of experience with the difficulties and complexities of the current procedures.

The efforts of administrations to develop the concept of periodic multilateral planning meetings will likely produce agreed upon improvements to the current procedures for obtaining geostationary orbit/frequency assignments in the FSS. 
Intersessional Work and Preparations for WARC-ORB-88

With the Space WARC being held in two sessions (1985 and 1988), there is a 3 year intersessional period in which to develop the necessary technical data and analyses and to establish the formal positions of the individual administrations. The intersessional technical work will be accomplished by administrations via the CCIR, and each administration will internally prepare its formal positions on the issues of WARC-0RB-88.

\section{Possible Agenda Items for WARC-ORB-88}

The first session of the Space WARC has recommended items for the agenda of the second session. The administrative council of the ITU will consider these items, previous resolutions and recominendations, and inputs from administrations, to arrive at a final agenda. Items likely to be on the WARC-ORB- 88 agenda include:

(1) Establishment of an allotment plan and regulatory procedures for the FSS.

(2) Establishment of improved regulatory procedures.

(3) Adoption of technical standards, parameters and criteria.

(4) Establishment of a feederlink plan for ITU Regions 1 and 3, associated with the $12 \mathrm{GHz}$ downlink plan for the BSS.

BSS.

(5) Consideration of allocations for sound

(6) Consideration of a suitable frequency band for the BSS to accommodate high definition television.

The preparatory work being conducted by the several CCIR study groups and the administrations will touch upon all items of the WARC-ORB-88 agenda.

\section{Preparatory Work}

The intersessional work topics identified by the first session of the Space WARC include:

- Technical parameters of satellite systems, such as frequency band pairing, orbit sectorization, generalized parameters for planning, earth station antennas, polarization discrimination, and sharing criteria.

- Computer software development for planning.

- Bi-directional use of frequencies for satellite communications.

- Satellite sound broadcasting systems technical parameters.

- High definition television transmissions by satellite - technical parameters, frequencies, and sharing aspects.
To accomplish this intersessional work the CCIR has proposed to use existing Interim Working Parties of the Study Groups and to organize a Joint Interim Working Party (JIWP) of the eight CCIR study groups concerned. This JIWP would meet in November 1986 and again in late 1987, with a Final Report available in February 1988.

The various administrations are also performing preparatory work during the intersessional period. In the United States, the Federal Communications Commission has maintained the Industry Advisory Committee to coordinate and collect the efforts of U.S. industry. On the government side, the Interagency Radio Advisory Committee (IRAC) has continued ad hoc committee 178 to similarly lead and coordinate the work. Also, the existing U.S. national CCIR structure is being used to channel technical inputs to the CCIR. In other administrations similar efforts are in progress.

\section{Concluding Remarks}

The 1985 Space WARC has made some fundamental decisions regarding the planning of space services. An allotment planning method has been identified for certain frequency bands in the fixed satellite service. Other frequency bands are subject to improved procedures for access by administrations. Between now and the next session of the Space WARC, there w111 be an intense period of preparatory work, during which technical studies will be conducted, planning software will be developed, and administrations will establish their positions on the 1ssues. At the 1988 Space WARC, the FSS allotment plan will likely be developed and agreed upon, as will the improved procedures. The decade following the 1988 Conference will apply the test of history to the outputs of this two session Space WARC. In the year 2000, we will be able to look back and assess which of the planning methods used (allotment planning, improved procedures, or another method) has been the most effective in guaranteeing equitable access to the geostationary orbit by all countries.

\section{References}

1. Technical Bases for the World Administrative Radio Conference on the Use of the Geostationary-Satellite Orbit and the Planning of the Space Services Utilizing It (WARC-ORB (T), Report of the CCIR Conference Preparatory Meeting (CPM), Joint Meeting, Study Groups $1,2,4,5,7,8,9,10$ and 11 , Geneva, June 25 - July 20, 1984, Parts I and II, International Telecommunications Union, Geneva, Switzerland, 1984.

2. Final Acts, WARC-ORB-85, International Telecommunications Union, Geneva, Switzerland, 1985.

3. Report to the Second Session of the Conference, and, Addendum to Report to the Second Session of the Conference, World Administrative Radio Conference on the Use of the Geostationary-Satellite Orbit and the Planning of Space Services Utilizing It, First Session, Geneva, 1985, International Telecommunications Union, Geneva, Switzer1 and, 1985. 
TABLE I. - MAJOR CHARACTERISTICS OF THE ALLOTMENT PLANNING METHOD

\begin{tabular}{|c|c|c|}
\hline Service & & FSS \\
\hline Frequencies & $\begin{array}{l}\text { downlink } \\
\text { feederlink } \\
\text { downlink } \\
\text { feederlink }\end{array}$ & $\begin{array}{l}4500-4800 \mathrm{MHz} \\
300 \mathrm{MHz} \text { in band } \\
6425-7075 \mathrm{MHz} \\
10.70-10.95 \mathrm{GHz} \text { and } \\
11.20-11.45 \mathrm{GHz} \\
12.75-13.25 \mathrm{GHz}\end{array}$ \\
\hline Total bandwidth & & $800 \mathrm{MHz}$ \\
\hline $\begin{array}{l}\text { National systems, providi } \\
\text { domestic service, with } \\
\text { provision for sub-regio } \\
\text { service }\end{array}$ & & \\
\hline Allotments & & $\begin{array}{l}\text { at least one per ITU } \\
\text { member } \\
\text { an orbital position } \\
\text { in a predetermined } \\
\text { arc } \\
800 \mathrm{MHz} \text { bandwidth }\end{array}$ \\
\hline Uuration & & 10 years, minımum \\
\hline Existing systems & & to be included in the plan. \\
\hline $\begin{array}{l}\text { Procedures for converting } \\
\text { an al lotment into a } \\
\text { assignment }\end{array}$ & & $\begin{array}{l}\text { to be determined by } \\
\text { WARC-0RB- } 88\end{array}$ \\
\hline
\end{tabular}

TABLE II. - MAJOR CHARACTERISTICS OF PLANNING BY IMPROVED PROCEDURES

\begin{tabular}{|c|c|c|}
\hline Service & & FSS \\
\hline Frequencies & $\begin{array}{l}\text { downl ink } \\
\text { feederlink } \\
\text { downl ink } \\
\text { feederlink } \\
\text { downl ink } \\
\text { feederl ink }\end{array}$ & $\begin{array}{l}3700-4200 \mathrm{MHz} \\
5850-6425 \mathrm{MHz} \\
10.95 \text { to } 11.20 \mathrm{GHz} \\
11.45 \text { to } 11.70 \mathrm{GHz} \\
11.70 \text { to } 12.20 \mathrm{GHz} \text { in } \\
\text { Region } 2 \\
12.50 \text { to } 12.75 \mathrm{GHz} \text { in } \\
\text { Regions } 1 \text { and } 3 \\
14.00 \text { to } 14.50 \mathrm{GHz} \\
18.10 \text { to } 20.20 \mathrm{GHz} \\
27.00 \text { to } 30.00 \mathrm{GHz}\end{array}$ \\
\hline $\begin{array}{l}\text { Multilateral planning } \\
\text { meetings }\end{array}$ & & $\begin{array}{l}\text { convened periodically } \\
\text { provide access to } \\
\text { GSO/spectrum resources } \\
\text { simple matters of access } \\
\text { or modification dealt } \\
\text { with between adminis- } \\
\text { trations } \\
\text { new and separate procedure } \\
\text { nature and status con- } \\
\text { sidered by WARC-ORB-88 }\end{array}$ \\
\hline Possible approach & & See flowchart (Fig. 1) \\
\hline
\end{tabular}




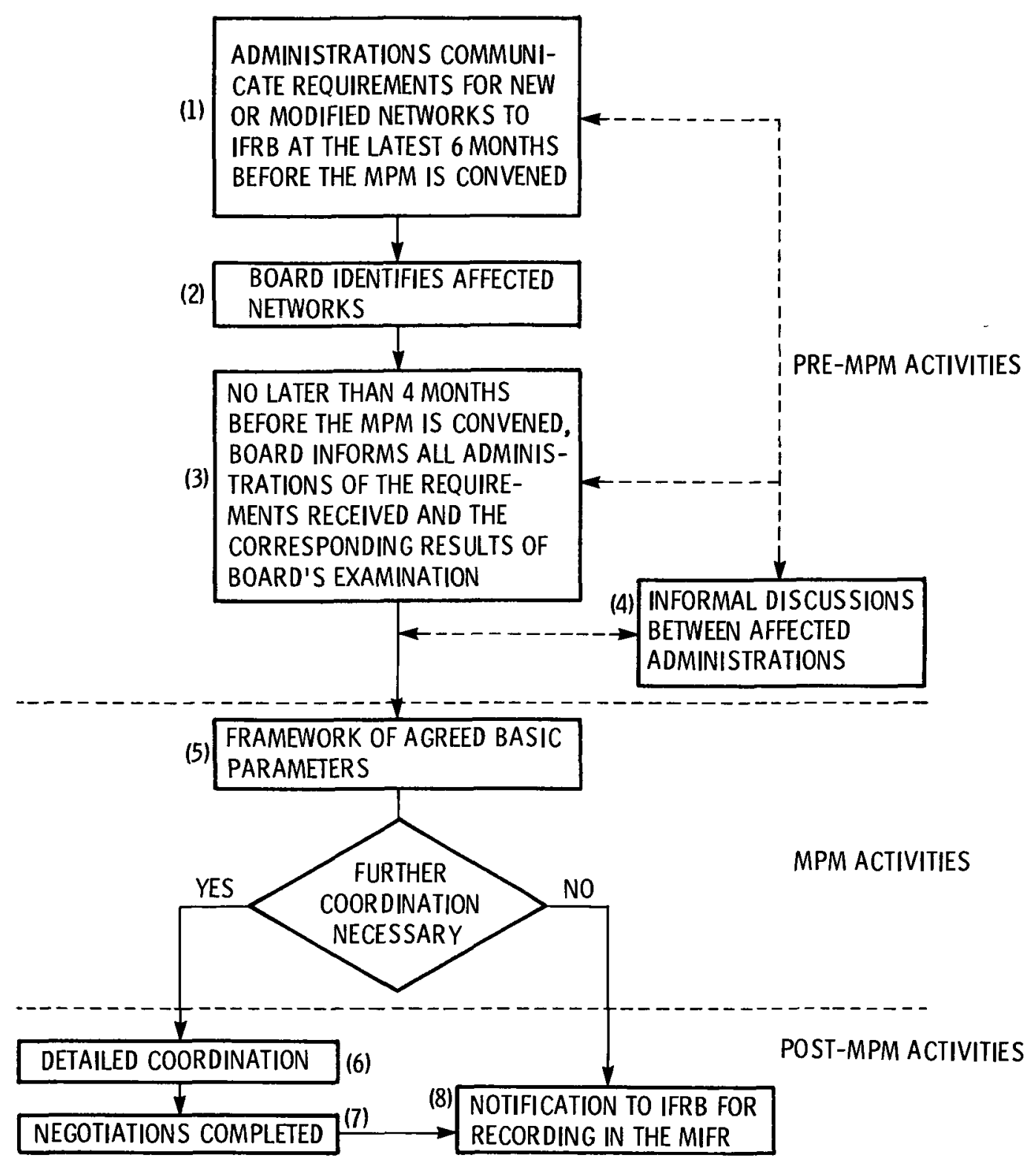

Figure 1. - Flowchart for a proposed approach to multi-lateral planning meetings (MPM's). 


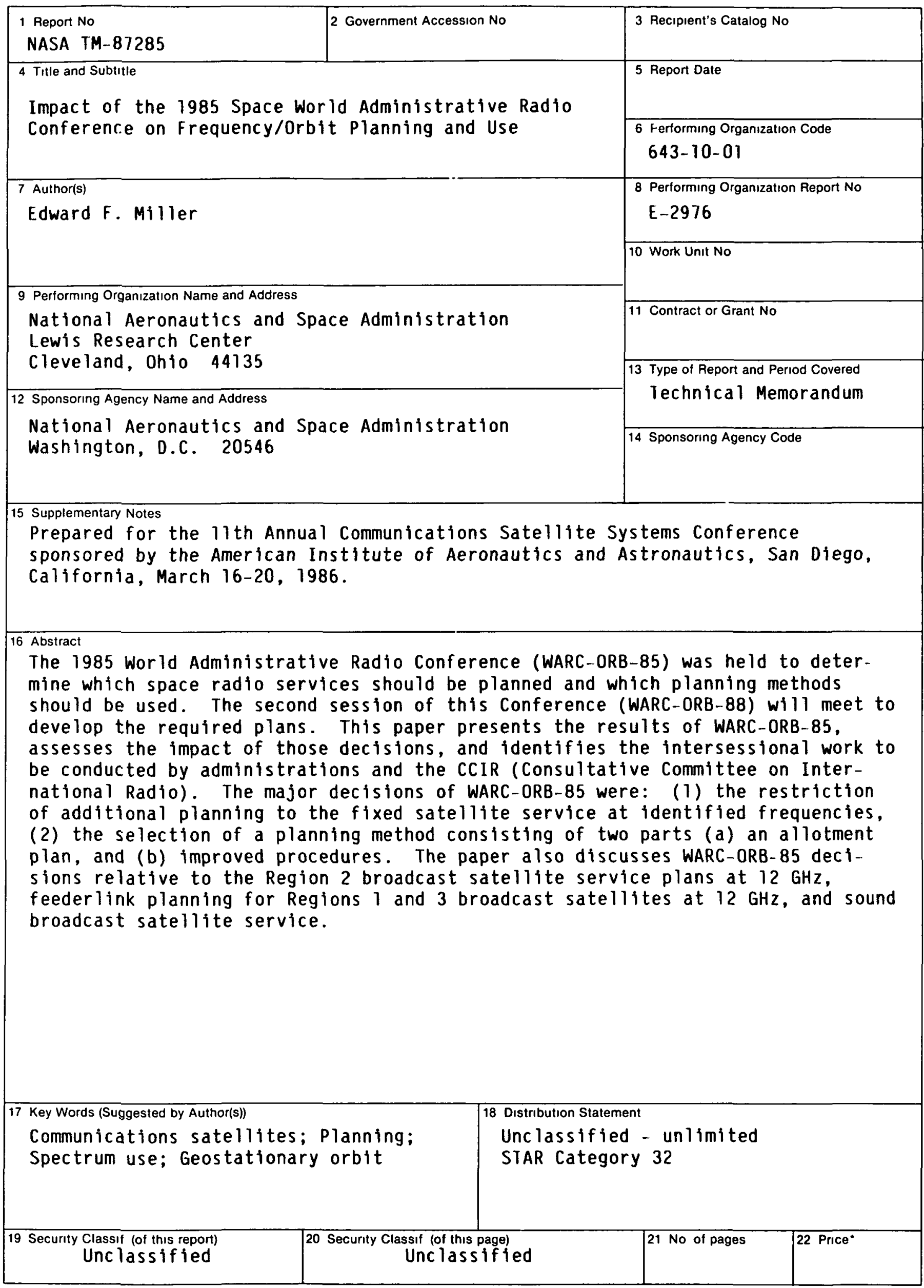

*For sale by the National Technıcal Information Service, Sprıngfield, Virginıa 22161 
Natıonal Aeronautıcs and

Space Administratıon

Lewis Research Center

Cleveland Ohıo 44135

Official Business

Penalty for Pitvato Use $\mathbf{5 0 0}$
SECOND CLASS MAIL

ADDRESS CORRECTION REQUESTED

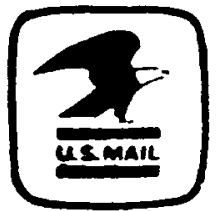

Postage and Fees Pard National Aeronautics and

Space Administration NASA-451 